\title{
Serological profiles in the connective tissue diseases in Zimbabwean patients
}

\author{
PAUL DAVIS, MICHAEL STEIN, HELGA LEY, AND CAROL JOHNSTON \\ From the Departments of Medicine, University of Zimbabwe, Harare, Zimbabwe; and the University of \\ Alberta, Edmonton, Alberta, Canada
}

SUMMARY The serological profiles of 104 Zimbabwean patients with clinically diagnosed connective tissue diseases were determined. The prevalence of rheumatoid factor was less than would have been expected in other geographical groups, but the prevalence of antinuclear antibodies was similar. Despite considerable racial, socioeconomic, and genetic differences in our patient group compared with other previously published studies the specificity and sensitivity of antinuclear antibodies, notably to DNA and Sm, correlated well with clinical diagnoses. This study validates the use of these serological tests in the investigation of this group of patients.

The development of assays for the production of serological profiles has proved to be a useful adjunct to the clinical diagnosis of patients with connective tissue diseases. Whereas assays such as those for rheumatoid factor subdivide patients into those with seropositive and seronegative polyarthritis, assays such as those for double stranded DNA antibodies have greater specificity in disease diagnosis. In addition, the detection of a variety of other antinuclear antibodies has proved to be useful in the diagnosis of other subsets of rheumatic diseases. Thus anti-Sm antibodies, anti-RNP antibodies, and anticentromere antibodies have variable specificity for conditions such as systemic lupus erythematosus, mixed connective tissue disease, and the CREST variant (calcinosis, Raynaud's phenomenon, oesophageal dysmotility, sclerodactyly, telangiectasia) of scleroderma respectively. Most reports to date have measured the specificity and sensitivity of these serological tests and profiles in European or North American patients. ${ }^{12}$ The connective tissue diseases commonly seen in rheumatological practice in these countries are reportedly uncommon on the southern African continent in blacks. ${ }^{34}$ For this reason, as well as the lack of appropriate technology, the spectrum of rheumatic diseases in Africa has not been as well defined as in other continents. We have recently studied a group of black Zimbabwean patients with rheumatic diseases in an attempt to

Accepted for publication 14 May 1988

Correspondence to Dr Paul Davis, Division of Rheumatology. Department of Medicine. University of Alberta, Edmonton, Alberta T6G 2G3, Canada. determine whether the serological profiles in these patients have the same specificity as that reported elsewhere in other distinctly different racial and genetic groups.

\section{Patients and methods}

Over a period of six months 104 patients with rheumatic diseases seen in a rheumatic diseases clinic at the University of Zimbabwe medical school were studied. There were 73 women and 31 men with an age range of 12-61 years. Patients had established disease of greater than six months' duration and were enrolled into the study on their first visit between the months of January and June 1987. Only patients who could be clinically diagnosed according to standard clinical syndromes or criteria were included in the study. Patients with rheumatoid arthritis fulfilled the criteria for the diagnosis of the disease. ${ }^{5}$ Patients with systemic lupus erythematosus (SLE) fulfilled the American Rheumatism Association preliminary criteria for the classification of lupus erythematosus ${ }^{6}$ as has previously been validated in a local population of black Zimbabweans with this condition. ${ }^{7}$ Patients with ankylosing spondylitis fulfilled the New York criteria for the diagnosis of the disease. ${ }^{8}$ All patients had stage IV sacroiliitis radiographically. The diagnoses of scleroderma, polymyositis, and Reiter's syndrome/ reactive arthritis were all made on clinical grounds with radiographic or biochemical confirmation, or both, as appropriate. Most patients were members of the Shona tribe and were a mixture of both rural and urban dwellers. All patients were clinically 
assessed, blood drawn, and serum stored at $-20^{\circ} \mathrm{C}$ for future serological investigations. Serological serum assessments were performed in batches by one trained technologist under the direct supervision of one rheumatologist in the research laboratories of the department of medicine at the University of Zimbabwe.

\section{RHEUMATOID FACTOR ASSAY}

A latex agglutination slide test kit was used (DadeMicro Scan, Miami, Florida) for the qualitative and quantitative determination of rheumatoid factors in serum. One drop of the patient's serum, diluted 1:20, was added to the slide and mixed with one drop of latex reagent. The slide was gently rocked for two minutes. Positive and negative controls were included on each slide for accurate visual interpretation of test sera results. Positive reactions indicating the presence of rheumatoid factor were detected by agglutination, and negative reactions by the absence of agglutination. Strength of the agglutination was graded from $1+$ to $4+$.

ANTINUCLEAR ANTIBODY (ANA) ASSAY ANA assays were performed on two different substrates. Commercially prepared kits containing slides of $\mathrm{HEp}_{2}$ cells and mouse stomach/kidney were used (Kallestad Laboratories Inc, Austin, Texas). Lyophilised positive and negative controls were reconstituted and included in each run.

Briefly, patient serum samples were diluted 1:20 and placed on appropriate wells, followed by incubation in a moist chamber at room temperature for 30 minutes. Each slide was then washed for 15 minutes in phosphate buffered saline (PBS). Each slide was dried with blotting strips, returned to the moist chamber, and each well covered with a drop of fluorescein conjugated goat antiserum to human total immunoglobulins. After a further 30 minute incubation at room temperature and a final 15 minute wash in PBS the slides were again dried and mounting media applied followed by a coverslip. The slides were read with a fluorescent microscope. The pattern of positive nuclear staining was assessed as either homogeneous, coarse speckled, or nucleolar staining in subtype.

ANTI-dSDNA ANTIBODY ASSAY

Anti-dsDNA antibody assays were performed using Crithidia luciliae as a substrate. Commercially prepared kits containing slides of Crithidia luciliae were used (Kallestad Laboratories Inc, Austin, Texas). Lyophilised positive and negative controls were reconstituted and included in each run.

Patient serum samples were diluted 1:10 and placed on appropriate wells, followed by incubation in a moist chamber at room temperature for 30 minutes. Each slide was then washed fors? 15 minutes in PBS. Each slide was dried witho blotting strips, returned to the moist chamber, andō each well covered with a drop of fluorescein conju- $\frac{\overline{-n}}{-}$ gated goat antiserum to human total immunoglobins.$\stackrel{\square}{\Omega}$ After a further 30 minutes' incubation at roomo temperature, and a final 15 minute wash in PBS, the slides were again dried and mounting media applied ${ }^{\circ}$ followed by a coverslip. The slides were read with a $\overrightarrow{-}$ fluorescent microscope. Positive immunofluorescento straining of the kinetoplast was regarded as positive result for DNA antibodies.

EXTRACTABLE NUCLEAR ANTIGENS ASSAY Extractable nuclear antigens were detected by the Ouchterlony immunodiffusion technique using commercially prepared kits obtained from Kallestad Laboratories Inc (Austin, Texas). These kits screen for Sm/RNP or SSA/SSB. Agarose plates with precut holes were filled with either patient o₹ control serum samples in the outer wells. Totat antigen source was contained in an extract of calpo thymus, which was placed in the centre well. Once wells were filled, the lids were replaced onto the agarose gel plates, which were then incubated for 24 hours in a moist chamber at room temperature Precipitin lines were determined over a view box:ू This procedure was used in the screening, identifica tion, and titre of patient serum samples. Once th $\overrightarrow{5}$ precipitin lines had formed specific antibody detection was made using lines of non-identity partial identity, or identity to known controls.

\section{Results}

Of the 104 patients whose sera were studied, 49 had rheumatoid arthritis, 20 SLE, three scleroderma five polymyositis, 16 Reiter's/reactive arthritis, sito ankylosing spondylitis, and five gout. Table 1 show? the distribution of serological abnormalities found ip these patients. Data from patients with Reiter's reactive arthritis, ankylosing spondylitis, and gouts all of whom were uniformly negative for all the serological assays performed, are not included. ON the 49 patients with rheumatoid arthritis, $18(37 \%)^{\omega}$ were seropositive for rheumatoid factor. Fifteen $(31 \%)$ had positive antinuclear antibodies detected Of these, seven had a coarse speckled pattern of staining, three a homogeneous pattern, and five patients were weakly positive. No serum samples from patients with rheumatoid arthritis had antie. bodies to double stranded DNA or Sm. Six of the्ष seven sera with a coarse speckled positive staining ANA contained antibodies to RNP, two to SSA? and one to SSB. 
Table 1 Distribution of serological abnormalities

\begin{tabular}{|c|c|c|c|c|c|c|c|c|}
\hline \multirow[t]{2}{*}{ Diagnosis } & \multirow[t]{2}{*}{ No } & \multirow[t]{2}{*}{$R F$} & \multirow{2}{*}{$\begin{array}{l}\text { ANA } \\
{\text { (pattern })^{*}}^{*}\end{array}$} & \multirow[t]{2}{*}{$D N A$} & \multirow[t]{2}{*}{$S m$} & \multicolumn{3}{|c|}{ Extractable nuclear antigens } \\
\hline & & & & & & $R N P$ & $S S A$ & $S S B$ \\
\hline Rheumatoid arthritis & 49 & 18 & $\begin{array}{l}15 \\
(7 \mathrm{csp} \\
3 \text { homo } \\
5 \mathrm{wk})\end{array}$ & - & - & $\begin{array}{l}6 \\
6\end{array}$ & $\begin{array}{l}2 \\
2\end{array}$ & $\begin{array}{l}1 \\
1\end{array}$ \\
\hline Systemic lupus erythematosus & 20 & 3 & $\begin{array}{l}17 \\
(8 \mathrm{csp} \\
8 \text { homo } \\
1 \text { wk) }\end{array}$ & $\begin{array}{r}11 \\
4 \\
7\end{array}$ & $\begin{array}{l}7 \\
4 \\
3\end{array}$ & $\begin{array}{l}7 \\
4 \\
3\end{array}$ & $\begin{array}{l}4 \\
3 \\
1\end{array}$ & $\begin{array}{l}7 \\
3 \\
4\end{array}$ \\
\hline Scleroderma & 3 & 0 & $\begin{array}{l}1 \\
(1 \text { nucl })\end{array}$ & - & - & - & - & - \\
\hline Polymyositis & 5 & 0 & $\begin{array}{l}4 \\
(2 \mathrm{csp} \\
1 \text { nucl } \\
1 \text { wk) }\end{array}$ & - & - & 1 & 1 & - \\
\hline
\end{tabular}

${ }^{*} \mathrm{csp}=$ coarse speckled; homo=homogeneous; nucl=nucleolar $;$ wk = weak positive

Of the 20 patients with SLE, three $(15 \%)$ were seropositive for rheumatoid factor. Seventeen patients $(85 \%)$ had antinuclear antibodies, of which eight had a homogeneous pattern, eight were coarse speckled, and one weakly positive. Eleven $(55 \%)$ of the patients had antibodies to double stranded DNA and seven had anti-Sm antibodies. Seven patients had antibodies to RNP, four to SSA, and seven to SSB. Of the three patients with scleroderma, one had antinuclear antibody which was of a nucleolar pattern. No other antibodies were detected in this group of patients. Of the five patients with polymyositis, four $(80 \%)$ had antinuclear antibodies, of which two were coarse speckled pattern, one nucleolar pattern, and one weak positive. One of the sera with a positive coarse speckled antinuclear antibody staining pattern contained both antibodies to RNP and SSA.

Studies performed on serum samples from 30 random control patients were uniformly negative for all antibodies.

\section{Discussion}

A review of patients attending a rheumatic disease clinic in Zimbabwe has shown that contrary to previously published data the spectrum of rheumatic diseases in this population is somewhat similar to that seen in North American and European studies. As patients attending this clinic were highly selected by the nature of the referral practice in this geographical area, and as this was not a formal epidemiological study, the results may be biased. Certainly they indicate that the size of the problem is greater than previously anticipated. Furthermore, as many of these patients, by virtue of the referral practice, had longstanding disease it might be anticipated that in the population as a whole taking into account the patients with less severe disease the size of the clinical problem is even greater. When diseases such as rheumatic fever and septic arthritis were excluded the types of rheumatic disease seen in this population were similar to those observed in other population groups. In particular, rheumatoid arthritis and SLE were the two major conditions observed with fewer patients manifesting features of other multisystem connective tissue diseases. Seronegative spondarthritides and reactive arthritis were observed, though ankylosing spondylitis itself was relatively uncommon as previously described,,$^{34}$ possibly owing to genetic differences in this racial group 9 or to the nature of local referral patterns.

The prevalence of rheumatoid factor was surprisingly low (37\%) in rheumatoid arthritis. Many of these patients had longstanding and quite severe active and deforming disease and a higher prevalence of rheumatoid factor might have been anticipated. Greenwood in Nigeria using a latex agglutination test found the prevalence of rheumatoid factor $(13 \%)$ was similar in patients with rheumatoid arthritis and in healthy controls. ${ }^{10}$ This was possibly the result of chronic exposure to endemic diseases. The prevalence of rheumatoid factor in healthy Zimbabweans is $0.4 \% .^{11}$ There was no clinical evidence to suggest that these patients with seronegative rheumatoid arthritis had any other cause for their arthropathy, such as psoriatic arthritis. The prevalence of antinuclear antibodies was somewhat higher than normally seen in a group of patients with rheumatoid arthritis, but this in itself may well be a 
reflection of the severity and duration of the disease that many of these patients had experienced. A number of patients had coarse speckled staining antinuclear antibodies, and in all these cases there was a good correlation between the pattern of antinuclear antibody and the presence of antibodies to RNP.

Of the 20 patients with SLE, the pattern of serology was very much as expected in other patient population groups. Rheumatoid factor was found in a minority of patients and most patients $(85 \%)$ had antinuclear antibodies with an equal distribution between coarse speckled and homogeneous pattern. Three patients who were ANA negative fulfilled the American Rheumatism Association preliminary criteria for the classification of SLE. DNA antibodies were found in $55 \%$ of the patients, and this was the only condition in which they were detected. The level of DNA antibody tended to correlate as anticipated clinically with the patient's clinical status. Antibodies to extractable nuclear antigens were seen in high prevalence in this group of patients. Antibodies to $\mathrm{Sm}$ were only observed in patients with SLE. Antibodies to RNP, SSA, and SSB were also observed in high prevalence in this group of patients, though it was not possible to distinguish any specific correlation between these subsets of extractable nuclear antigens and any specific clinical features of the patient's disease.

Antinuclear antibodies were detected in some of the patients with scleroderma and polymyositis. None of these patients had rheumatoid factor, DNA antibodies, or antibodies to Sm. The prevalence of antibodies to extractable nuclear antigens was low. As might have been anticipated from previous population studies the serology in patients with reactive arthritis, seronegative spondarthritides, and gout was uniformly negative.

Studies on the specific serological tests applicable to the connective tissue diseases have not previously been performed in this geographical population.
Our results show that the prevalence of connective tissue disease is perhaps somewhat higher than has? previously been observed in this region. The distri? bution of the rheumatic diseases also appears to be similar to that reported in North American ane European groups. This study has also shown that the spectrum of serological abnormalities in this group i\& similar to that previously described and that the profile of serological abnormalities correlates welP with specific disease entities as previously reported in other geographical areas. This study validates the use of serological testing in this group of diseases if Zimbabwe despite the considerable genetic and socioeconomic differences which exist in this population group when compared with other groups studied.

\section{References}

1 Fritzler M J. Antinuclear antibodies in the investigation rheumatoid diseases. Bull Rheum Dis 1985; 35: 9-10.

2 Reichlin M. Antinuclear antibodies. In: Kelley W N, Harris E D, Ruddy S, Sledge C B, eds. Textbook of rheumatology ${ }_{\infty}$ 2nd ed. Philadelphia: Saunders, 1985: 690-707.

3 Gelfand M. 'Medical' arthritis in African practice. Cent Afr J Med 1969; 15: 131-5.

4 Lutalo S K. Chronic inflammatory rheumatic diseases in blac Zimbabweans. Ann Rheum Dis 1985; 44: 121-5.

5 Ropes M W, Bennett G A, Cobb S, Jacox R, Jessar R A Revision of diagnostic criteria in rheumatoid arthritis. Bu同 Rheum Dis 1958; 9: 175-6.

6 Tan E M, Cohen A S, Fries J F, et al. The 1982 revised criteri $\overrightarrow{3}$ for the classification of systemic lupus erythematosus. Arthritis Rheum 1982; 25: 1271-7.

7 Taylor H G, Stein C M. Systemic lupus erythematosus Zimbabwe. Ann Rheum Dis 1986; 45: 645-8.

8 Bennett P H, Wood P N H. Third International Symposium oñ population studies of the rheumatic diseases. Amsterdamo Excerpta Medica, 1968: 456.

9 Lowe R F. The distribution of the blood group and HL antigens in Zimbabwean Africans. Cent Afr J Med 1981; 27\% 11-18.

10 Greenwood B M. Polyarthritis in Western Nigeria. I. Rheum? atoid arthritis. Ann Rheum Dis 1969; 28: 488-96.

11 Ellis B P B. Leprosy and the rheumatoid factor. Cent Afr J Me 1978; 24: 8-9. 